\title{
Cytokeratin 20-negative Merkel cell carcinoma is infrequently associated with the Merkel cell polyomavirus
}

\author{
Andrew G Miner ${ }^{1,2}$, Rajiv M Patel ${ }^{3,4}$, Deborah A Wilson ${ }^{2}$, Gary W Procop ${ }^{2}$, Eugen C Minca ${ }^{2}$, \\ Douglas R Fullen ${ }^{3,4}$, Paul W Harms ${ }^{3,4}$ and Steven D Billings ${ }^{2}$ \\ ${ }^{1}$ Department of Dermatology, The Cleveland Clinic, Cleveland, OH, USA; ${ }^{2}$ Department of Pathology, \\ The Cleveland Clinic, Cleveland, OH, USA; ${ }^{3}$ Department of Pathology, University of Michigan, Ann Arbor, \\ MI, USA and ${ }^{4}$ Department of Dermatology, University of Michigan, Ann Arbor, MI, USA
}

\begin{abstract}
Merkel cell carcinoma is a rare, highly aggressive cutaneous neuroendocrine carcinoma most commonly seen in sun-damaged skin. Histologically, the tumor consists of primitive round cells with fine chromatin and numerous mitoses. Immunohistochemical stains demonstrate expression of neuroendocrine markers. In addition, cytokeratin 20 (CK20) is expressed in $\sim 95 \%$ of cases. In 2008, Merkel cell carcinoma was shown to be associated with a virus now known as Merkel cell polyomavirus in $\sim 80 \%$ of cases. Prognostic and mechanistic differences between Merkel cell polyomavirus-positive and Merkel cell polyomavirus-negative Merkel cell carcinoma may exist. There has been the suggestion that CK20-negative Merkel cell carcinomas less frequently harbor Merkel cell polyomavirus, but a systematic investigation for Merkel cell polyomavirus incidence in CK20negative Merkel cell carcinoma has not been done. To test the hypothesis that Merkel cell polyomavirus is less frequently associated with CK20-negative Merkel cell carcinoma, we investigated 13 CK20-negative Merkel cell carcinomas from the files of the Cleveland Clinic and the University of Michigan for the virus. The presence or absence of Merkel cell polyomavirus was determined by quantitative PCR performed for Large $T$ and small $T$ antigens, with sequencing of PCR products to confirm the presence of Merkel cell polyomavirus. Ten of these (77\%) were negative for Merkel cell polyomavirus and three $(23 \%)$ were positive for Merkel cell polyomavirus. Merkel cell polyomavirus is less common in CK20-negative Merkel cell carcinoma. Larger series and clinical follow-up may help to determine whether CK20-negative Merkel cell carcinoma is mechanistically and prognostically unique.

Modern Pathology (2015) 28, 498-504; doi:10.1038/modpathol.2014.148; published online 14 November 2014
\end{abstract}

In 1875 Friedrich Merkel described the Tastzellen, or 'touch cells,' that now bear his name. ${ }^{1}$ Nearly 100 years later, in 1972, Cyril Toker described trabecular carcinoma, named after its characteristic growth pattern, and favored a sweat gland origin for this tumor. ${ }^{2}$ Later ultrastructural studies demonstrated dense core neurosecretory granules within the cells of 'trabecular carcinoma,' and subsequently the Merkel cell became a favored candidate for this malignancy's cell of origin. $^{3}$ Recent evidence suggests that the cell of origin for Merkel cell carcinoma may be a Merkel cell precursor stem cell. ${ }^{4}$

Correspondence: Dr SD Billings, 9500 Euclid Avenue L25, Cleveland, OH 44195, USA.

E-mail: billins@ccf.org

Received 8 July 2014; revised 2 September 2014; accepted 3 September 2014; published online 14 November 2014
Merkel cell carcinoma is among the most lethal cutaneous carcinomas, with significant mortality rate. ${ }^{5}$ Therefore, accurate distinction of Merkel cell carcinoma from histologically similar tumors is critical for prompt and appropriate management. Merkel cell carcinoma may display histologic overlap with basaloid or small cell cutaneous malignancies including basal cell carcinoma, adnexal carcinoma, lymphoma, and small-cell melanoma, although in most cases morphologic distinction is possible between Merkel cell carcinoma and these entities. ${ }^{6}$ However, Merkel cell carcinoma cannot be morphologically distinguished from cutaneous metastases of small cell carcinoma. Therefore, immunohistochemistry is critical for definitive diagnosis. Characteristically, Merkel cell carcinoma is positive for cytokeratins and neuroendocrine markers like synaptophysin, chromogranin, neurofilament, and neuron-specific enolase. ${ }^{6,7}$ Cytokeratin 20 has 
become a standard marker for Merkel cell carcinoma and is positive in $\sim 95 \%$ of cases, frequently with a classic paranuclear dot-like pattern of staining. ${ }^{7-9}$ Cytokeratin 20 expression is absent in most other small round cell malignancies including metastatic small cell lung carcinoma, as well as less-aggressive cutaneous malignancies such as basal cell carcinoma. ${ }^{6-8}$

Lack of cytokeratin 20 expression has been described in $\sim 5 \%$ of Merkel cell carcinoma. ${ }^{6,10-12}$ Diagnosis of cytokeratin 20-negative Merkel cell carcinoma typically involves immunohistochemical studies for cytokeratins other than cytokeratin 20 (including AE1/3, Cam5.2, or CK7) and neuroendocrine markers. The important differential diagnosis in this context is metastatic small cell lung carcinoma. Thyroid transcription factor- 1 is a useful marker for small cell lung carcinoma; although it may be negative in $10-15 \%$ of cases and has been reported to be expressed in exceptional cases of Merkel cell carcinoma. ${ }^{7,8,13,14}$ Neurofilament protein expression is frequently observed in Merkel cell carcinoma but not in small cell lung carcinoma., ${ }^{7,15}$ Although it has been speculated that cytokeratin 20 negativity may be the result of de-differentiation, ${ }^{16}$ it is unclear whether the absence of cytokeratin 20 expression is an isolated finding in Merkel cell carcinoma, or whether these tumors are characterized by distinct molecular changes and prognostic differences relative to cytokeratin 20-positive Merkel cell carcinoma.

A breakthrough in understanding of the molecular pathogenesis of Merkel cell carcinoma came in 2008, when Merkel cell polyomavirus was shown to be present in a high percentage of Merkel cell carcinomas. ${ }^{17}$ Merkel cell polyomavirus may promote tumorigenesis via oncogenic actions of viral small $\mathrm{T}$ antigen and large $\mathrm{T}$ antigen, which are generated from a single gene via alternative splicing. ${ }^{5}$ Merkel cell polyomavirus associated with Merkel cell carcinoma displays tumor-specific mutations or deletions in large $\mathrm{T}$ antigen which render the virus replication deficient, a common characteristic of oncogenic viruses. ${ }^{5,18}$ Although numerous assays for Merkel cell polyomavirus detection have been reported, PCR targeting small $\mathrm{T}$ antigen and/or the 5' region of large $\mathrm{T}$ antigen is commonly used and highly sensitive. ${ }^{19-21}$

Although present in the majority of Merkel cell carcinoma, Merkel cell polyomavirus has not been commonly observed in other malignancies. In particular, the presence of Merkel cell polyomavirus is highly specific for Merkel cell carcinoma relative to small cell lung carcinoma, ${ }^{12,22-24}$ and hence might be considered as a diagnostic marker in challenging cases including cytokeratin 20-negative Merkel cell carcinoma. However, studies examining the association between cytokeratin 20 negativity and the presence of Merkel cell polyomavirus in Merkel cell carcinoma have been limited to case reports or incidental findings within larger case series. To our knowledge, there have been seven total reported cases in the literature of cytokeratin 20-negative cutaneous Merkel cell carcinoma assessed for Merkel cell polyomavirus status; of these, five were negative for Merkel cell polyomavirus. ${ }^{12,13,25,26}$ We hypothesized that Merkel cell polyomavirus is less frequently associated with cytokeratin 20-negative Merkel cell carcinomas.

Better understanding of the incidence of Merkel cell polyomavirus in cytokeratin 20-negative Merkel cell carcinoma has implications for the diagnostic utility of Merkel cell polyomavirus in this setting and may yield clues regarding the molecular pathogenesis of this subset of Merkel cell carcinomas. Therefore, we examined the incidence of Merkel cell polyomavirus by PCR in a cohort of 13 cytokeratin 20-negative Merkel cell carcinoma tumors.

\section{Materials and methods}

\section{Case Selection}

All studies were conducted with prior approval by the Institutional Review Board. The archives of the Cleveland Clinic and the University of Michigan were searched for cytokeratin 20-negative Merkel cell carcinomas. For inclusion in the study, the tumors had to have typical histologic features of Merkel cell carcinoma and compatible immunohistochemical profiles including positivity for cytokeratins coupled with positivity for at least one neuroendocrine marker. The medical charts were reviewed, or for cases received in consultation, contributors or treating physicians were contacted to establish that the tumors were clinically consistent with Merkel cell carcinoma and that there was no evidence of a neuroendocrine carcinoma for a different site.

\section{Immunohistochemistry}

All of the immunohistochemical stains were reviewed. Most were performed at the time of initial diagnosis either by the referring institutions or at the Cleveland Clinic or the University of Michigan. A limited number of stains were performed at the Cleveland Clinic for the purposes of this study including cytokeratin 7 (DAKO, Carpinteria, CA, USA; clone OV-TL 12/30, dilution 1:40), neuron-specific enolase (DAKO; clone BBS/ NC/VI-H14, dilution 1:50), chromogranin A (DAKO; clone DAK-A3, dilution 1:100), and synaptophysin (BioGenex, Fremont, CA, USA; clone Snp88, prediluted) using the Ventana BenchMark XT or BenchMark Ultra autostainer (Ventana Medical Systems, Tucson, AZ, USA).

\section{DNA Extraction and PCR}

Five $4 \mu \mathrm{m}$ tissue sections per specimen were deparaffinized and DNA was extracted using the 
commercial microbead system (NucliSENS-easyMag, BioMírieux, Durham, NC, USA), following the manufacturer's instructions, as previously described. ${ }^{23}$ DNA quantification was performed and diluted if necessary to achieve DNA concentrations between 3 and $50 \mathrm{ng} / \mu \mathrm{l}$. Qualitative PCR was performed for Merkel cell polyomavirus using previously reported primers sets including two (LT1 and MCVPS1) targeting the large $\mathrm{T}$ antigen and a third (LT3) predominantly targeting the small $\mathrm{T}$ antigen unique region (Table 1). ${ }^{19}$ Quantitative PCR for $\beta$-globin was used as the positive control to confirm the presence of amplifiable DNA. Negative controls included purified, distilled water and a sample of aortic valve tissue from a patient unaffected by Merkel cell carcinoma.

Quantitative PCR with LT1 and LT3 primer sets was performed using SybrGreen fluorescence (Life Technologies, Carlsbad, CA, USA). Threshold cycles were calculated for all samples. All samples were subsequently submitted for Sanger sequencing to confirm the presence of Merkel cell polyomavirus.

MCVPS1 quantitative PCR was performed using a TaqMan ${ }^{\circledR}$ probe (Life Technologies) for its high sensitivity and specificity. ${ }^{27}$ The TaqMan ${ }^{\circledR}$ probe used was designed to specifically identify nucleotides 1104-1123 (5'-3' sequence GGACCCGATATACCTCCCGAAC) within the sequence amplified by the MCVPS1 primer set. All 14 samples were evaluated with the MCVPS1 primer set in conjunction with the MCVPS1 TaqMan ${ }^{\circledR}$ probe.

Studies evaluating the melting temperature of double-stranded PCR products were consistent with expected melting temperatures of LT1 and LT3 double primer sets and support the results of PCR and sequencing.

\section{Results}

Thirteen cases of Merkel cell carcinoma, occurring in 7 men and 6 women ranging in age from 56 to 93 years (mean 72 ), were identified out of $\sim 380$ cases in the combined archives. The tumors arose on the head and neck $(n=7)$, upper extremities $(n=3)$, lower extremities $(n=2)$, and in an unspecified location $(n=1)$. None of the patients had evidence of a neuroendocrine carcinoma from another potential primary. Patients treated at the authors' institutions all had appropriate clinical evaluations, including radiologic staging studies. For all cases seen in consultation with the exception of one, we were able to obtain additional clinical information. None of the consultation cases had evidence of a neuroendocrine carcinoma elsewhere. These patients had detailed clinical and radiologic evaluations. For the case in which additional information was unable to be obtained, the patient was a 93-year-old man with a lesion on the nose (see below).

Histologically, the tumors showed characteristic features of Merkel cell carcinoma, including trabecular or nodular proliferations of primitive round cells with high nuclear-to-cytoplasmic ratios, frequent mitoses, and a stippled ('salt and pepper') chromatin pattern. Nuclear molding was present at least focally in six of the cases (Figure 1). There were no morphologic findings to suggest basal cell carcinoma or adnexal carcinoma with aberrant neuroendocrine marker expression.

All our cases were positive for at least one cytokeratin (Figure 2; Table 2); however, the most common pattern was diffuse cytoplasmic or

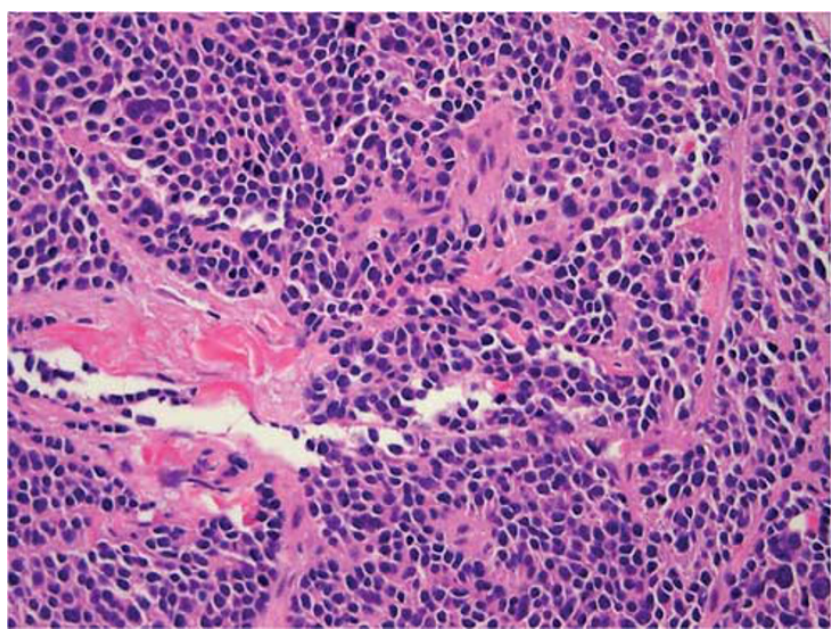

Figure 1 Histologic features of the cases. All of the cases of cytokeratin 20-negative Merkel cell carcinoma had typical histologic findings of Merkel cell carcinoma. The tumors were composed of cells with high nuclear-to-cytoplasmic ratios with a neuroendocrine chromatin pattern. Prominent nuclear molding was seen in six cases.

Table 1 Primers used for MCPyV detection (LT1, LT3, MCVPS1) and control ( $\beta$-globin)

\begin{tabular}{|c|c|c|c|c|c|c|}
\hline Primer & $\begin{array}{l}\text { NT } \\
\text { location }\end{array}$ & Forward sequence & Reverse sequence & Probe & $\begin{array}{l}\text { Amplicon } \\
\text { size (bp) }\end{array}$ & Reference \\
\hline LT1 & $1514-1953$ & TACAAGCACTCCACCAAAGC & TCCAATTACAGCTGGCCTCT & N/A & 440 & 19 \\
\hline LT3 & $571-879$ & TTGTCTCGCCAGCATTGTAG & ATATAGGGGCCTCGTCAACC & N/A & 308 & 19 \\
\hline MCVPS1 & 1071-1179 & TCAGCGTCCCAGGCTTCAGA & TGGTGGTCTCCTCTCTGCTACTG & $\begin{array}{l}\text { GGACCCGATAT } \\
\text { ACCTCCCGAAC }\end{array}$ & 109 & 19 \\
\hline$\beta$-Globin & & ACACAACTGTGTTCACTAGC & CAACTTCATCCACGTTCACC & N/A & 110 & \\
\hline
\end{tabular}

Abbreviations: bp, base pair; NT, nucleotide. 

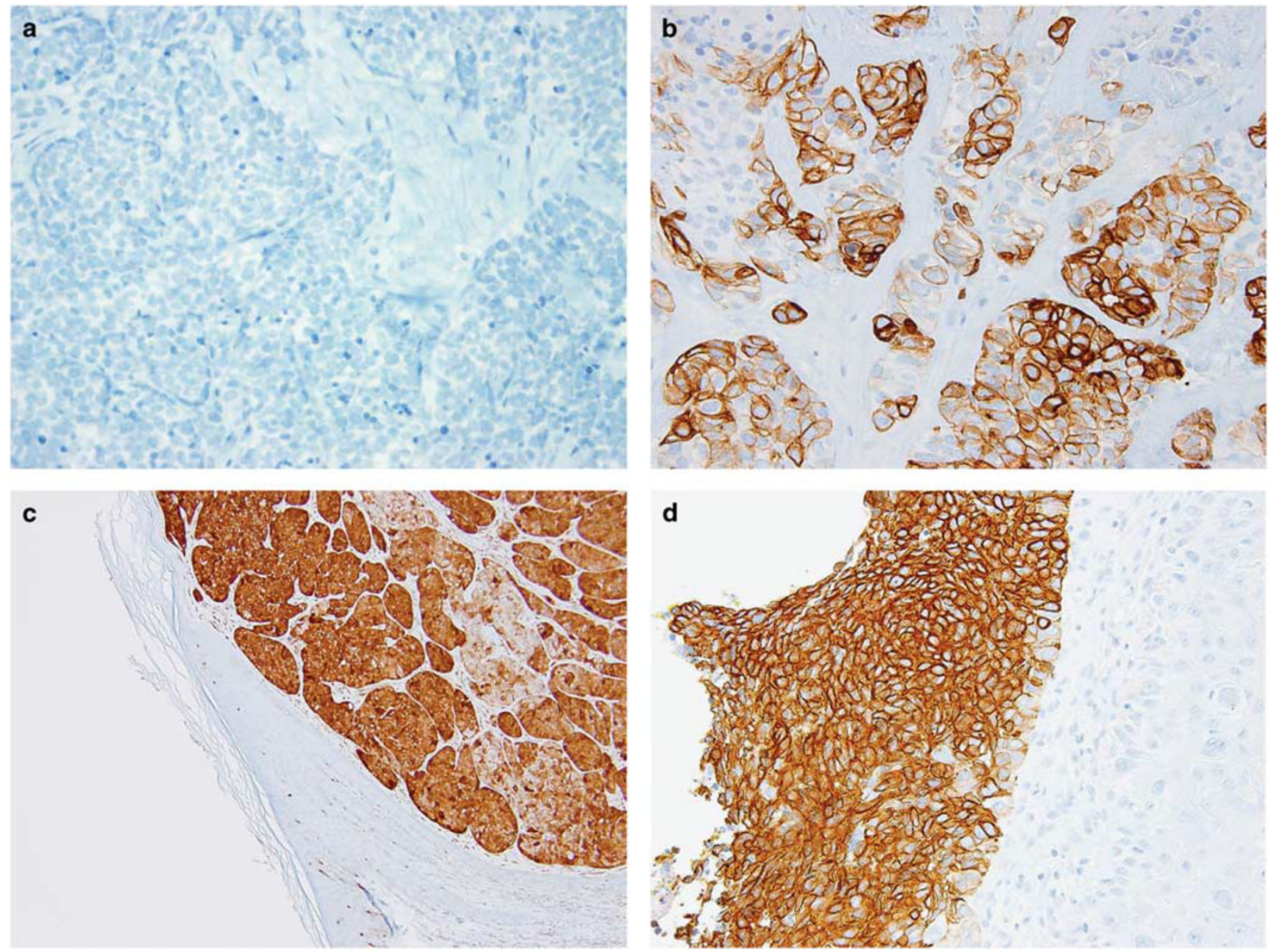

Figure 2 Summary of immunohistochemical stains. All specimens were negative for cytokeratin 20 (a); cytokeratin 7 was positive in a cytoplasmic, membranous pattern in two of our samples (b); all cases were positive for neuroendocrine markers such as neuron-specific enolase (c); other keratin immunohistochemical stains such as Cam5.2 usually had a diffuse cytoplasmic or membranous staining similar to stains for cytokeratin 7 rather than a perinuclear dot-like pattern (d).

membranous and not the usual paranuclear dot-like pattern. All had immunoreactivity for at least one neuroendocrine marker (Figure 2; Table 2). Synaptophysin was the most commonly positive neuroendocrine marker (6/8), while chromogranin was less sensitive (4/9). None of the cases tested were positive for thyroid transcription factor-1 (13/13). Dot-like immunoreactivity for neurofilament protein was seen in two of three consultation cases.

The one case in which there was no detailed clinical information had typical histologic features of Merkel cell carcinoma but also had a squamous cell carcinoma component that included overlying squamous cell carcinoma in situ. This case also exhibited dot-like immunoreactivity for neurofilament protein.

The specimens were analyzed by PCR for MCVPS1, LT1, LT3, and $\beta$-globin. Ten cases $(77 \%)$ were negative for Merkel cell polyomavirus. Three $(23 \%)$ were positive for Merkel cell polyomavirus (Figure 3). Of these, two were positive for all three primer sets tested, including MCVPS1 and LT1 (targeting large T antigen) and LT3 (predominantly targeting small $\mathrm{T}$ antigen). The remaining case was positive for MCVPS1 and LT3 (Table 3). PCR products for LT1 and LT3 were further analyzed by Sanger sequencing, which demonstrated $>98 \%$ similarity to the Merkel cell polyomavirus genome (NC_010277.1) for all PCR amplicons (Figure 4). Case 4 displayed a C1923T mutation resulting in a premature stop codon in large $\mathrm{T}$ antigen, consistent with a tumor-specific truncating mutation.

\section{Discussion}

Merkel cell carcinoma is a primary cutaneous neuroendocrine carcinoma that typically occurs in older, fair-skinned patients. Merkel cell carcinoma is aggressive with metastatic rates of $36-55 \%$ and overall 5-year mortality between 31 and $64 \% .^{28-30}$ The diagnosis of Merkel cell carcinoma is confirmed 
with immunohistochemical stains for distinction from other small cell malignancies, including metastatic small cell lung carcinoma. ${ }^{6-8}$ Particularly useful is cytokeratin 20, which is positive in $\sim 95 \%$ of Merkel cell carcinomas but negative in most small cell lung carcinomas. ${ }^{6-8}$

Increased insight into the pathogenesis of Merkel cell carcinoma was gained in 2008 with the discovery that Merkel cell polyomavirus was genomically integrated in a significant subset of Merkel cell carcinoma. ${ }^{17}$ Merkel cell polyomavirus appears to be a common constituent of normal microfauna on the skin of healthy individuals. ${ }^{5,31}$ However, evidence suggests that Merkel cell polyomavirus detected in Merkel cell carcinoma has an oncogenic role, rather than incidental detection of background infection by wild-type virus. Merkel cell polyomavirus in Merkel cell carcinoma displays clonal integration, high viral copy number, and tumorspecific mutations of large $\mathrm{T}$ antigen resulting in incapacity to replicate. ${ }^{5,17,18,32}$ Furthermore, in vitro studies support a role for Merkel cell polyomavirus $\mathrm{T}$ antigens, especially small $\mathrm{T}$ antigen, in transformation and cell survival. ${ }^{5}$

Table 2. Summary of immunohistochemical stains

\begin{tabular}{lr} 
Stain & Positive/Tota \\
\hline Cytokeratins & \\
Cytokeratin 20 & $0 / 13$ \\
Cytokeratin-7 & $2 / 12$ \\
AE1/AE3 & $11 / 11$ \\
Cam 5.2 & $2 / 4$ \\
Any cytokeratin & $13 / 13$ \\
Neuroendocrine markers & \\
NSE & \\
Synaptophysin & $2 / 3$ \\
Chromogranin & $7 / 9$ \\
CD56 & $4 / 10$ \\
Neurofilament & $3 / 4$ \\
Any neuroendocrine marker & $2 / 3$ \\
Other & $13 / 13$ \\
TTF-1 & \\
\hline
\end{tabular}

Abbreviations: CK20, cytokeratin 20; CK7, cytokeratin 7; NSE, neuron-specific enolase; TTF-1, thyroid transcription factor 1 .
Most studies have reported that a significant minority of Merkel cell carcinoma lack detectable Merkel cell polyomavirus, ${ }^{5}$ raising the question of how Merkel cell polyomavirus-negative tumors might differ from Merkel cell polyomavirus-positive tumors. Reports have been mixed regarding immunohistochemical and clinical differences between Merkel cell polyomavirus-positive and Merkel cell polyomavirus-negative tumors. ${ }^{31}$ Merkel cell carcinoma with squamous elements or coexisting squamous cell carcinoma is often Merkel cell polyomavirus negative. ${ }^{12,23,25,33-36}$ Recent findings indicate that Merkel cell polyomavirusnegative tumors may be associated with $R B 1$ inactivating mutations ${ }^{37}$ and (in a subset) PIK3CA activating mutations. ${ }^{38}$ Hence, although additional study is needed to clarify differences between Merkel cell polyomavirus-positive and Merkel cell polyomavirus-negative tumors, current data suggest that molecular differences exist that may have implications for immune-based or targeted therapy.

It is unclear what role Merkel cell polyomavirus plays in the rare subset of Merkel cell carcinoma that are cytokeratin 20 negative. We undertook a study to examine series of cytokeratin 20-negative Merkel cell carcinoma to further explore the prevalence of

Table 3 MCPyV positivity as detected by LT1 and LT3 (PCR, sequencing) and MCVPS1 (Taqman ${ }^{\circledR}$ probe-based PCR)

\begin{tabular}{lccc}
\hline Case & MCVPS1 & LT1 & LT3 \\
\hline 1 & - & - & - \\
2 & - & - & - \\
3 & - & - & - \\
4 & + & + & + \\
5 & - & - & - \\
6 & - & - & - \\
7 & - & - & - \\
8 & - & - & - \\
9 & - & - & - \\
10 & + & + & + \\
11 & - & - & - \\
12 & - & - & + \\
13 & + & - & + \\
MKL-1 & + & + & \\
\hline
\end{tabular}

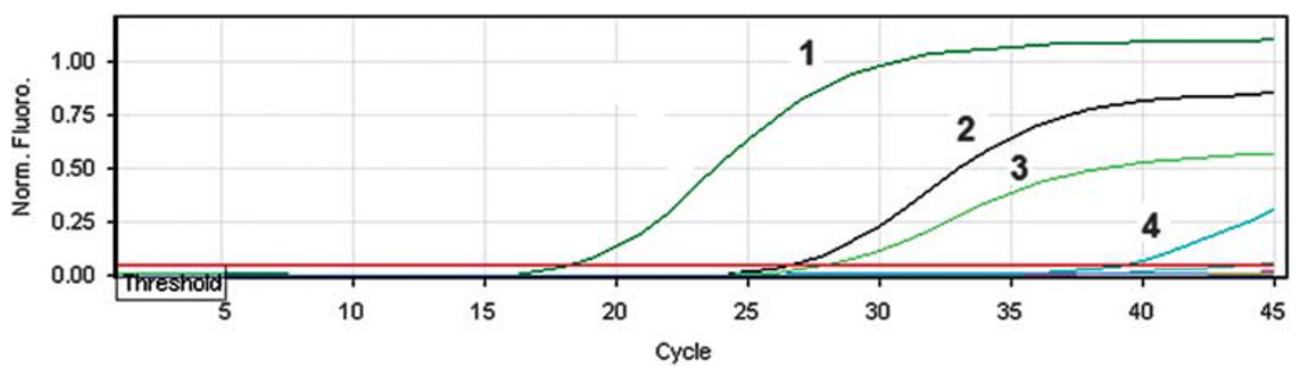

Figure 3 PCR melting curve analysis for Merkel cell polyomavirus. PCR melting curve for Merkel cell polyomavirus LT3: 1Amplification of the Merkel cell polyomavirus cell line in the positive control cell line. 2, 3, and 4 demonstrate the amplification of the MCV in patients 4,10 , and 13, respectively. All of the other specimens were negative for Merkel cell polyomavirus. 


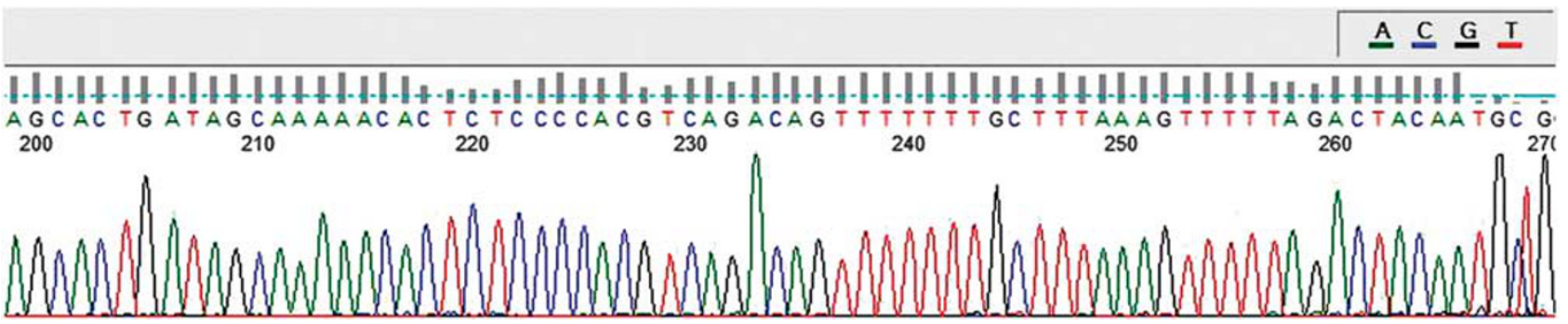

Figure 4 Example of Sanger sequencing for a Merkel cell polyomavirus-positive case. For the Merkel cell polyomavirus-positive cases, Sanger sequencing demonstrated $>98 \%$ similarity to the Merkel cell polyomavirus genome (NC_010277.1) for all PCR amplicons.

Merkel cell polyomavirus in this subset of Merkel cell carcinoma. Our PCR results suggest that Merkel cell polyomavirus is uncommon in cytokeratin 20negative Merkel cell carcinoma, as 10/13 (77\%) were negative for the virus. This finding agrees with the few previous reports of cytokeratin 20-negative Merkel cell carcinoma evaluated for Merkel cell polyomavirus, the majority of which were Merkel cell polyomavirus negative. ${ }^{12,13,25,26}$

These results have diagnostic implications. Lack of cytokeratin 20 expression may make definitive diagnosis of Merkel cell carcinoma challenging, and additional markers may be desirable in this context. Detection of Merkel cell polyomavirus either by immunohistochemistry or by molecular means has been proposed as a diagnostic test for Merkel cell carcinoma, which may aid in distinction from other carcinomas, including metastatic small cell carcinoma. ${ }^{12,22-24}$ Our results suggest that Merkel cell polyomavirus detection is insufficiently sensitive to be useful in the diagnosis of cytokeratin 20-negative Merkel cell carcinoma. Other markers such as thyroid transcription factor-1 and neurofilament may be more useful in this context. ${ }^{7,15,26}$

In summary, our data suggest that cytokeratin 20negative Merkel cell carcinoma is more likely to lack detectable Merkel cell polyomavirus. Further investigations will address whether Merkel cell polyomavirus-negative/cytokeratin 20-negative Merkel cell carcinoma displays genetic changes similar to other Merkel cell polyomavirus-negative Merkel cell carcinoma such as $R B 1$ mutations, or whether these tumors possess a unique spectrum of mutations and hence represent a distinct molecular subclass of Merkel cell carcinoma.

\section{Conclusions}

We have shown through three primer sets that cytokeratin 20-negative Merkel cell carcinoma is associated with a low incidence of Merkel cell polyomavirus positivity. Further study of cytokeratin 20-negative, Merkel cell polyomavirus-negative Merkel cell carcinoma may prove helpful in elucidating genetic changes and prognosis of this subset of Merkel cell carcinoma.

\section{Disclosure/conflict of interest}

The authors declare no conflict of interest.

\section{References}

1 Merkel F. Tastzellen and Tastkoerperchen bei den Hausthieren und beim Menschen. Arch Mikrosc Anat 1875;11:636-652.

2 Toker C. Trabecular carcinoma of the skin. Arch Dermatol 1972;105:107-110.

3 Tang CK, Toker C. Trabecular carcinoma of the skin: an ultrastructural study. Cancer 1978;42:2311-2321.

4 Tilling T, Moll I. Which are the cells of origin in Merkel cell carcinoma? J Skin Cancer 2012;2012:680410.

5 Spurgeon ME, Lambert PF. Merkel cell polyomavirus: a newly discovered human virus with oncogenic potential. Virology 2013;435:118-130.

6 Pulitzer MP, Amin BD, Busam KJ. Merkel cell carcinoma: review. Adv Anat Pathol 2009;16:135-144.

7 Bobos M, Hytiroglou P, Kostopoulos I, et al. Immunohistochemical distinction between Merkel cell carcinoma and small cell carcinoma of the lung. Am J Dermatopathol 2006;28:99-104.

8 Hanly AJ, Elgart GW, Jorda M, et al. Analysis of thyroid transcription factor-1 and cytokeratin 20 separates Merkel cell carcinoma from small cell carcinoma of lung. J Cutan Pathol 2000;27:118-120.

9 Moll R, Lowe A, Laufer J, et al. Cytokeratin 20 in human carcinomas. A new histodiagnostic marker detected by monoclonal antibodies. Am J Pathol 1992;140:427-447.

10 Calder KB, Coplowitz S, Schlauder S, et al. A case series and immunophenotypic analysis of CK20-/ CK7 + primary neuroendocrine carcinoma of the skin. J Cutan Pathol 2007;34:918-923.

11 Beer TW. Merkel cell carcinomas with CK20 negative and CK7 positive immunostaining. J Cutan Pathol 2009;36:385-386; author reply 387.

12 Busam KJ, Jungbluth AA, Rekthman N, et al. Merkel cell polyomavirus expression in Merkel cell carcinomas and its absence in combined tumors and pulmonary neuroendocrine carcinomas. Am J Surg Pathol 2009;33:1378-1385.

13 Koba S, Inoue T, Okawa T, et al. Merkel cell carcinoma with cytokeratin 20-negative and thyroid transcription factor-1-positive immunostaining admixed with squamous cell carcinoma. J Dermatol Sci 2011;64:77-79.

14 Reddi DM, Puri PK. Expression of focal TTF-1 expression in a case of CK7/CK20-positive Merkel cell carcinoma. J Cutan Pathol 2013;40:431-433. 
15 McCalmont TH. Paranuclear dots of neurofilament reliably identify Merkel cell carcinoma. J Cutan Pathol 2010;37:821-823.

16 Pilloni L, Manieli C, Senes G, et al. Merkel cell carcinoma with an unusual immunohistochemical profile. Eur J Histochem 2009;53:275-278.

17 Feng H, Shuda M, Chang Y, et al. Clonal integration of a polyomavirus in human Merkel cell carcinoma. Science 2008;319:1096-1100.

18 Shuda M, Feng H, Kwun HJ, et al. T antigen mutations are a human tumor-specific signature for Merkel cell polyomavirus. Proc Natl Acad Sci USA 2008;105: 16272-16277.

19 Duncavage EJ, Zehnbauer BA, Pfeifer JD. Prevalence of Merkel cell polyomavirus in Merkel cell carcinoma. Mod Pathol 2009;22:516-521.

20 Rodig SJ, Cheng J, Wardzala J, et al. Improved detection suggests all Merkel cell carcinomas harbor Merkel polyomavirus. J Clin Invest 2012;122: 4645-4653.

21 Shuda M, Kwun HJ, Feng H, et al. Human Merkel cell polyomavirus small $\mathrm{T}$ antigen is an oncoprotein targeting the 4E-BP1 translation regulator. J Clin Invest 2011;121:3623-3634.

22 Jung HS, Choi YL, Choi JS, et al. Detection of Merkel cell polyomavirus in Merkel cell carcinomas and small cell carcinomas by PCR and immunohistochemistry. Histol Histopathol 2011;26:1231-1241.

23 Ly TY, Walsh NM, Pasternak S. The spectrum of Merkel cell polyomavirus expression in Merkel cell carcinoma, in a variety of cutaneous neoplasms, and in neuroendocrine carcinomas from different anatomical sites. Hum Pathol 2012;43:557-566.

24 Paik JY, Hall G, Clarkson A, et al. Immunohistochemistry for Merkel cell polyomavirus is highly specific but not sensitive for the diagnosis of Merkel cell carcinoma in the Australian population. Hum Pathol 2011;42:1385-1390.

25 Ishida $M$, Okabe H. Merkel cell carcinoma concurrent with Bowen's disease: two cases, one with an unusual immunophenotype. J Cutan Pathol 2013;40: 839-843.

26 Andres C, Belloni B, Jaeger $\mathrm{T}$, et al. Immunohistochemical features of Merkel cell carcinoma in correlation with presence of Merkel cell polyomavirus DNA. Acta Derm Venereol 2011;91:722-723.
27 Satterfield BC, Bartosiewicz M, West JA, et al. Surpassing specificity limits of nucleic acid probes via cooperativity. J Mol Diagn 2010;12:359-367.

28 Erovic I, Erovic BM. Merkel cell carcinoma: the past, the present, and the future. J Skin Cancer 2013;2013: 929364.

29 Hughes MP, Hardee ME, Cornelius LA, et al. Merkel cell carcinoma: epidemiology, target, and therapy. Curr Dermatol Rep 2014;3:46-53.

30 Medina-Franco H, Urist MM, Fiveash J, et al. Multimodality treatment of Merkel cell carcinoma: case series and literature review of 1024 cases. Ann Surg Oncol 2001;8:204-208.

31 Coursaget P, Samimi M, Nicol JT, et al. Human Merkel cell polyomavirus: virological background and clinical implications. APMIS 2013;121:755-769.

32 Laude HC, Jonchere B, Maubec E, et al. Distinct Merkel cell polyomavirus molecular features in tumour and non tumour specimens from patients with Merkel cell carcinoma. PLoS Pathog 2010;6:e1001076.

33 Iwasaki T, Matsushita M, Kuwamoto S, et al. Usefulness of significant morphologic characteristics in distinguishing between Merkel cell polyomaviruspositive and Merkel cell polyomavirus-negative Merkel cell carcinomas. Hum Pathol 2013;44:1912-1917.

34 Martin B, Poblet E, Rios JJ, et al. Merkel cell carcinoma with divergent differentiation: histopathological and immunohistochemical study of 15 cases with PCR analysis for Merkel cell polyomavirus. Histopathology 2013;62:711-722.

35 Mitteldorf C, Mertz KD, Fernandez-Figueras MT, et al. Detection of Merkel cell polyomavirus and human papillomaviruses in Merkel cell carcinoma combined with squamous cell carcinoma in immunocompetent European patients. Am J Dermatopathol 2012;34: $506-510$

36 Kuwamoto S, Higaki H, Kanai K, et al. Association of Merkel cell polyomavirus infection with morphologic differences in Merkel cell carcinoma. Hum Pathol 2011;42:632-640.

37 Cimino PJ, Robirds DH, Tripp SR, et al. Retinoblastoma gene mutations detected by whole exome sequencing of Merkel cell carcinoma. Mod Pathol 2014;27:1073-1087.

38 Nardi V, Song Y, Santamaria-Barria JA, et al. Activation of PI3K signaling in Merkel cell carcinoma. Clin Cancer Res 2012;18:1227-1236. 